\title{
Graphene-doped carbon xerogel combining high electrical conductivity and surface area for optimized aqueous supercapacitors
}

\author{
María Canal-Rodríguez ${ }^{(1)}$, Ana Arenillas ${ }^{(1)}$, Natalia Rey-Raap ${ }^{(1)}$, Gloria Ramos \\ Fernández $^{(2)}$, Ignacio Martín-Gullón ${ }^{(2)}$, J. Angel Menéndez ${ }^{(1) *}$ \\ (1) Instituto Nacional del Carbón, CSIC, Apartado 73, 33080 Oviedo, Spain \\ (2) Chemical Engineering Department, University of Alicante, Alicante 03690, Spain
}

\begin{abstract}
A graphene doped carbon xerogel was synthesized by simply replacing the water (solvent) by an aqueous well-dispersed graphene oxide stable suspension in the precursor mixture used for the synthesis of the organic xerogel. During the carbonization of the organic xerogel, the graphene oxide sheets are reduced to graphene, which is embedded and well dispersed within the carbon xerogel matrix. Only a small minimum amount of graphene oxide is necessary to interconnect the graphene sheets throughout the carbon xerogel. This material has both a high porosity and an excellent electrical conductivity so that, when used as electrode in aqueous supercapacitors at high current density, it provides them with $25 \%$ more capacitance and $100 \%$ more power than the undoped carbon xerogels. The synthesis conditions, characteristics of the carbons and how these affect the electrical conductivity and performance of the materials in the supercapacitors are discussed.
\end{abstract}

Keywords: carbon xerogel, graphene oxide, graphene, supercapacitor 


\section{Introduction}

Energy storage and power delivery are currently acquiring increasing importance as society becomes more concerned with the supply of clean energy and its sustainability. As a consequence, special attention is paid to the development of renewable energy sources and the need to store the energy generated for future supply or demand. Thus, to overcome the fluctuations in the grid, not only a system that stores energy is needed but also one able to supply it as a quick response, i.e. a high power density device. On the other hand, devices which can store large amounts of energy and have long cycle life are also preferred [1]. Unfortunately, at the moment there is no single device capable of dealing with the main both requirements, i.e. the supply of a large amount of energy and a high power density [2]. Batteries are generally preferred for high energy density applications. However their power density is low and their charge-discharge processes often involve irreversibility in the short-medium term, and so the cycle-life of batteries is usually limited. By contrast, in supercapacitors (or electrochemical capacitors) the energy storage mechanism is a reversible process, enabling them to offer a long durability (over $10^{6}$ cycles). Moreover, supercapacitors are capable of supplying high power densities, i.e. more than $10 \mathrm{~kW} \mathrm{~kg}^{-1}$ [3]. Nevertheless, their capacitances are still lower than those of batteries, and therefore $R \& D$ in this field is focused on finding new materials for supercapacitors that improve its current performance [4-14].

The ideal active material for use in electrodes of supercapacitors would be a material with a large surface area (i.e. a high volume of micropores for storing the ions of the dissociated electrolyte), with a sufficient amount of transport pores (i.e. mesopores for the electrolyte to pass through and reach the entire micropore structure), and a high 
electrical conductivity to ensure an easy and fast transportation of electrons. Typically, carbon materials do not have both a high electrical conductivity and at the same time a high specific surface area (see Table 1). This is because a good electrical conductivity requires an ordered and crystalline carbon structure, like that of graphite, which implies a poor porous structure. On the other hand, a high surface area carbon with a large pore volume implies, in general, a disordered amorphous carbon structure with a low electrical conductivity. Nevertheless, there are some exceptions to this general rule as can be seen in Table 1.

Table 1. BET specific surface areas and electrical conductivities of selected carbon materials

\begin{tabular}{|c|c|c|c|c|}
\hline Carbon Material & Reference & $\begin{array}{c}\mathrm{S}_{\mathrm{BET}} \\
\left(\mathrm{m}^{2} \mathrm{~g}^{-1}\right)\end{array}$ & $\begin{array}{l}\text { K-FPP } \\
\left(\mathrm{S} \mathrm{m}^{-1}\right)\end{array}$ & $\begin{array}{c}\mathrm{K}-\mathrm{COM} \times 10^{2} \\
\left(\mathrm{~S} \mathrm{~m}^{-1}\right)\end{array}$ \\
\hline Biomass derived activated carbon & {$[15]$} & 2800 & 13 & 3 \\
\hline Graphene doped carbon xerogel & This work & 1556 & 310 & 125 \\
\hline Polimer derived activated carbon & [16] & 836 & 30 & 10 \\
\hline Graphene/carbon composite aerogel & {$[6]$} & 763 & 528 & 216 \\
\hline Comercial (biomass) activated carbon & {$[17]$} & 711 & 12 & 2 \\
\hline CNT aerogel & [18] & 635 & 150 & 59 \\
\hline Chemicaly treated carbon black & [19] & 559 & 249 & 100 \\
\hline Graphene aerogel & {$[7]$} & 244 & 133 & 52 \\
\hline Graphite (= to basal plane) & {$[20]$} & $<100$ & 6057 & 2500 \\
\hline Graphite $(\perp$ to basal plane $)$ & {$[20]$} & $<100$ & 15 & 3 \\
\hline
\end{tabular}

K-FPP: Electric conductivity measured using four point probing. K-COM: Electric conductivity measured using the compression method. Note that the values obtained by these two methods are not directly comparable. However, they can be converted each other using the equations from [21]

A possible solution to overcome this problem might be to embed a highly conductive ordered carbon, like nanotubes or graphene [5-11], inside a porous carbon in such a way that the conductive carbon creates a network that facilitates electron transportation, while retaining the porosity of the material that acts as matrix. However, the synthesis of such a carbon is not straightforward. Ling et al. [9] attempted to dope a porous carbon directly with graphene using an ionic liquid template approach, but with difficulties for a good dispersion of the conductive material along the amorphous carbon 
matrix. Other authors $[5,6,8]$, doped the porous carbonaceous materials with different quantities of graphene oxide and obtained the final graphene-doped carbon by subjecting the material to subsequent thermal treatment. However, either these doped materials do not have a large pore volume, which is the key to the performance of supercapacitors, or the amount of doping is extremely high (i.e. up to $10 \mathrm{wt} \%$ in the precursor solution), being in some cases considered as carbon composites by the authors [5-6], and resulting in less cost-effective carbons.

The solution proposed in this work consists in obtaining a carbon xerogel, with the appropriate porous structure in terms of micro and mesoporosity by using a suspension (in water) of graphene oxide (GO) as solvent, instead of just water which is the usual method. This is not only a simple process but it is also relatively cheap (compared to some of those described above) since it uses GO (cheaper than graphene), that is then converted into graphene by carbothermal reduction. The process is fast and simple, and in addition, it might open up a new market for GO, thereby redressing the, until now, low commercialization of this product.

\section{Experimental}

\subsection{Materials}

An organic xerogel (MWOX) was synthesized by the polycondensation of resorcinol (R) with formaldehyde (F) in water (W) using a $1 \mathrm{M}$ solution of $\mathrm{NaOH}$ to adjust the $\mathrm{pH}$. Firstly, the resorcinol was dissolved in deionized water in a flask under magnetic stirring. Then, formaldehyde $(37 \mathrm{wt} \%)$ was added to the mixture and kept under stirring until a homogeneous solution was obtained. The gel was synthesized using a molar ratio $(\mathrm{R} / \mathrm{F})$ of 0.5 , a dilution ratio (D) of 5.7 and a $\mathrm{pH}$ of 6.5 . Finally, the solution was placed inside a microwave oven at $85{ }^{\circ} \mathrm{C}$ for $5 \mathrm{~h}$ to undergo gelation, ageing and drying [12-14, 
$22,23]$. It is worth noting that this process is much shorter than the other processes reported in the bibliography that usually take several days [24, 25].

Two organic xerogels were doped with Graphene Oxide (GO). The synthesis procedure was identical to that used for MWOX except that $50 \mathrm{wt} \%$ and $100 \mathrm{wt} \%$ of the solvent (W) were replaced with an aqueous $5 \mathrm{mg} / \mathrm{mL}$ GO suspension, so that the GO concentrations in the precursor solutions were of $0.11 \mathrm{wt} \%$ and $0.22 \mathrm{wt} \%$ respectively. Given that no GO was lost during the gelation, ageing and drying steps (maximum temperature of $85^{\circ} \mathrm{C}$ ), the resulting doped organic xerogels had GO contents of 0.23 wt $\%$ (MWOX-0.23) and $0.46 \mathrm{wt} \%$ (MWOX-0.46) respectively.

GO suspension was produced by liquid phase exfoliation by ultrasonication of graphite oxide. Graphite oxide was synthetized by modified Hummers-Offeman method starting of natural graphite (NG) flakes BNB90, purchased to Imerys Graphite and Carbon (Bodio, Switzerland) [26]. Basically, $1 \mathrm{~g}$ of graphite, $200 \mathrm{ml} \mathrm{of} \mathrm{H}_{2} \mathrm{SO}_{4}$ and $1 \mathrm{~g}$ of $\mathrm{NaNO}_{3}$ were mixed and stirred at room temperature. After $3 \mathrm{~h}, 4 \mathrm{~g}$ of $\mathrm{KMnO}_{4}$ were added and the suspension was stirred for $2 \mathrm{~h}$. Subsequently, the temperature was increased to $60^{\circ} \mathrm{C}$ and kept for $1 \mathrm{~h}$. Once the reaction was completed, it was cooled down to room temperature, and poured into $400 \mathrm{ml}$ of cold water with $40 \mathrm{ml}$ of $\mathrm{H}_{2} \mathrm{O}_{2}$, in order to prevent $\mathrm{MnO}_{2}$ precipitation. After several water washing/filtration procedures, the solid graphite oxide product was dried overnight at $65^{\circ} \mathrm{C}$. Finally, graphite oxide powder $(1 \mathrm{~g})$ was introduced in deionized water $(200 \mathrm{~mL})$ and exfoliated into GO by high-energy sonication (QSonica Ultrasonic Q500) at $30 \mathrm{~W}$ for $2 \mathrm{~h}$, alternating cycles of $60 \mathrm{~s}$ in ON mode and $30 \mathrm{~s}$ in OFF mode.

The organic xerogels were then subjected to a one-step carbonization/activation process in a horizontal tubular reactor under a $\mathrm{CO}_{2}$ flow of $100 \mathrm{ml} / \mathrm{min}$. The heating rate used 
was $50{ }^{\circ} \mathrm{C} / \mathrm{min}$ up to $1000^{\circ} \mathrm{C}$. This temperature was then kept constant for the time necessary to obtain a surface area of ca. $1600 \mathrm{~m}^{2} / \mathrm{g}$. The overall yields attained in these processes were: $13 \mathrm{wt} \%, 18 \mathrm{wt} \%$ and $15 \mathrm{wt} \%$ for MWOX, MWOX-0.23 and MWOX0.46 , respectively. It has to be noted that the yields are relatively low because the former organic xerogel have more than $50 \mathrm{wt} \%$ of volatiles, moisture and residual reagents that simple evolve during the thermal heating.

In order to estimate the amount of reduced GO (which from now on will be referred to simply as "graphene") contained in the resulting carbon xerogels, it was assumed that (i) GO is completely reduced to graphene during the carbonization/activation process. Therefore, all its oxygen content ( $27 \mathrm{wt} \%$, according to its elemental analysis by means of a LECO TRUSPEC Micro-O analyser) is gone during the pyrolysis and (ii) the $\mathrm{CO}_{2}$ does not gasify the graphene but the more amorphous carbon structures instead. On the basis of these assumptions, the final percentages of graphene in the activated xerogels were ca. $1 \mathrm{wt} \%$ (MWAX-1) and $2 \mathrm{wt} \%$ (MWAX-2) respectively. Since this assumption is the only way to obtain an estimation of the $\mathrm{wt} \%$ of graphene present in the doped carbon xerogels it should be noted that these values are only approximate.

Apart from the above mentioned samples, a commercial activated carbon (YP-50F by Kuraray) specifically recommended for use in supercapacitor electrodes (and one of the most widely used currently in commercial ultracapacitors), was also included in this study for comparative proposes.

\subsection{Porous and chemical characterization}

The textural characteristics of the xerogels were evaluated on the basis of $\mathrm{N}_{2}$ adsorption-desorption isotherms recorded at $77 \mathrm{~K}$ (Micromeritics Tristar 3020). 
Adsorption-desorption isotherms are shown in Figure S1. Parameters such as $\mathbf{8}_{\mathrm{EET}}$ and $V_{\text {milore }}$ were calculated by applying the Brunauer-Emmett-Teller (BET) and DubininRaduskevich (DR) equations respectively, to the nitrogen adsorption isotherms. The total pore volume $(\mathrm{Vp})$ was determined from the amount of nitrogen adsorbed at saturation point $\left(\mathrm{p} / \mathrm{p}^{0}=0.99\right)$.

The micro/nano-metric surface morphology of the materials was examined by Highresolution transmission electron microscopy (HRTEM) using a JEOL JEM-2100F microscope operated at an accelerating voltage of $200 \mathrm{kV}$, equipped with a field emission gun (FEG) and an ultra-high resolution pole-piece that provided a pointresolution better than $0.19 \mathrm{~nm}$. The samples were dispersed in ethanol, sonicated and sprayed on a carbon-coated copper grid and then allowed to air-dry.

$\mathrm{C}, \mathrm{H}$ and $\mathrm{N}$ contents of the materials were measured in a LECO-CHNS-932 microanalyzer, while the O content was determined in a LECO-TF-900 device.

The point of zero charge (pHpzc) was determined introducing $250 \mathrm{mg}$ of sample into a test tube and adding each day a certain volume of distilled water to modify the mass concentration of the suspension. The suspension must be closed and under continuous stirring. Each day the $\mathrm{pH}$ is measured and the $\mathrm{pHpzc}$ value is obtained from the plateau of the $\mathrm{pH}$ evolution profile [27].

Temperature-programmed desorption (TPD) experiments were performed on a Micromeritics AutoChem II analyzer, by heating the samples up to $1000{ }^{\circ} \mathrm{C}$ under an Argon flow of $50 \mathrm{~cm}^{3} \mathrm{~min}^{-1}$ at a heating rate of $10{ }^{\circ} \mathrm{C} \mathrm{min}-1$. The amount of $\mathrm{CO}$ and $\mathrm{CO}_{2}$ desorbed was monitored in a mass spectrometer (OmniStar Pfeiffer). 


\subsection{Electrochemical characterization}

In order to study the electrochemical behaviour of the MWAX samples, disc-shaped electrodes were prepared by mixing the active carbon xerogels (90 wt\%) and polytetrafluoroethylene (PTFE) binder (10 wt\%). A homogeneous mixture of both compounds was obtained and rolled out in order to obtain a homogeneous thin film. Electrodes were manufactured by punching pellets from this film. Subsequently, the electrodes were pressed and dried $[14,21]$.The electrodes were 100-200 $\mu \mathrm{m}$ thick, $1 \mathrm{~cm}$ wide and weighed around 3-5 mg.

The electric conductivity of the materials was obtained by evaluating their sheet resistivity of the disc-shaped electrodes using the four-point probe technique (FPP) (model SR-4-6L, Everbeing) based on the Van der Pauw equation [3].

The electrochemical measurements were performed using a two-electrode testing cell (Teflon Swagelok $\left.{ }^{\circledR}\right)$ using stainless steel as current collector, a fibre glass separator $(400 \mu \mathrm{m})$ and two electrodes of the materials studied. The equipment used was a potentiostat/galvanostat VMP Biologic and $\mathrm{H}_{2} \mathrm{SO}_{4} 1 \mathrm{M}$ as electrolyte. Electrochemical impedance spectroscopy (EIS) analysis at open-circuit voltage $\left(\begin{array}{ll}0 & \mathrm{~V}\end{array}\right)$ within the frequency range of $1 \mathrm{mHz}$ to $100 \mathrm{kHz}$ and $10 \mathrm{mV} \mathrm{AC}$ amplitude, galvanostatic charge/discharge measurements at several current density (in the range of 0.1-16 $\mathrm{A} \mathrm{g}^{-1}$ ) with $\mathrm{U}=1.0 \mathrm{~V}$ and cyclic voltammetry tests at $2 \mathrm{mVs}^{-1}$ in a voltage window from 0.6 to $1.2 \mathrm{~V}$, were performed. 
The capacitance value of one electrode was calculated from the galvanostatic chargedischarge plots according to the following expression:

$$
C=2 \cdot \frac{I}{d V_{t} t_{d t}}
$$

where $\mathrm{C}$ is the specific capacitance of the electrode $\left(\mathrm{F} \mathrm{g}^{-1}\right)$, I is the current density applied $\left(\mathrm{A} \mathrm{g}^{-1}\right)$ and $\mathrm{dV} / \mathrm{dt}$ is the slope of the discharge line $\left(\mathrm{V} \mathrm{s}^{-1}\right)$. With this values it is also possible to calculate the energy density $\left(\mathrm{E}\right.$, in $\left.\mathrm{Wh} \mathrm{kg}^{-1}\right)$ and the power density per electrode of the supercapacitor $\left(\mathrm{P}\right.$, in $\left.\mathrm{W} \mathrm{kg}^{-1}\right)$ as follows [28]:

$$
\begin{gathered}
E=\begin{array}{c}
C \cdot[\Delta E]^{2} \\
2 \cdot 3600 \cdot m_{\theta}
\end{array} \\
P=\frac{(\Delta E-\Delta U)^{2}}{4 \cdot E S E \cdot m_{\theta}}
\end{gathered}
$$

where $\mathrm{C}$ is the capacitance of the carbon electrode (in farads, F), $\Delta \mathrm{E}$ is the poweroperated window (in volts, V), $\Delta \mathrm{U}$ corresponds to the ohmic fall (in volts, V), ESR is the equivalent series resistance (in ohms, $\Omega$ ) and $\mathrm{m}_{\mathrm{e}}$ is the active mass of the electrode (in kilograms, kg).

\section{Results and discussion}

The results of the chemical analysis of the four materials used in this study (Table 2) show that these materials have a virtually identical composition. They are almost pure carbons with less than a $3 \mathrm{wt} \%$ heteroatoms content. There is a significant difference, however, between the $\mathrm{pH}_{\mathrm{pzc}}$ of the three carbon xerogels and that of the commercial 
activated carbon. Thus, although all of them are of a basic nature, the $\mathrm{pH}_{\mathrm{pzc}}$ of YP-50F is almost two units lower.

Table 2. Chemical properties of the carbons studied

\begin{tabular}{lllll}
\hline & \multicolumn{3}{l}{ Elemental Analysis (wt $\% \mathrm{db})$} & \\
\cline { 2 - 4 } Sample & $\mathrm{C}$ & $\mathrm{H}$ & $\mathrm{O}$ & $\mathrm{pHPZC}$ \\
\hline MWAX & 97.1 & 0.3 & 2.7 & 9.3 \\
MWAX-1 & 97.7 & 0.5 & 1.8 & 9.4 \\
MWAX-2 & 97.0 & 0.2 & 2.8 & 9.3 \\
\hline YP-50F & 97.6 & 0.3 & 2.1 & 7.3 \\
\hline
\end{tabular}

This can be due to the different acidic/basic character of the oxygen functionalities of these carbons. Thus, as shown in Figure 1, the carbon xerogels have a larger (compared to YP-50F) amount of CO-releasing surface groups, which are generally either neutral or basic groups such as phenols and carbonyls [29, 30]. Moreover, YP-50F contains a certain amount oxygen-containing surface groups that release $\mathrm{CO}_{2}$ between $600{ }^{\circ} \mathrm{C}$ and $900{ }^{\circ} \mathrm{C}$. These functionalities, which are absent in the carbon xerogel, are attributed to anhydride and lactone-type groups, which are of an acidic nature [29, 30]. Therefore, given that the amount of oxygen surface groups is very low in both samples (i.e. YP50F and MWAX), it seems clear that basic surface groups are predominant in MWAX, whereas acid surface groups are more abundant in $\mathrm{YP}-50 \mathrm{~F}$, in accordance with the $\mathrm{pH}_{\mathrm{pzc}}$ values in Table 2. 

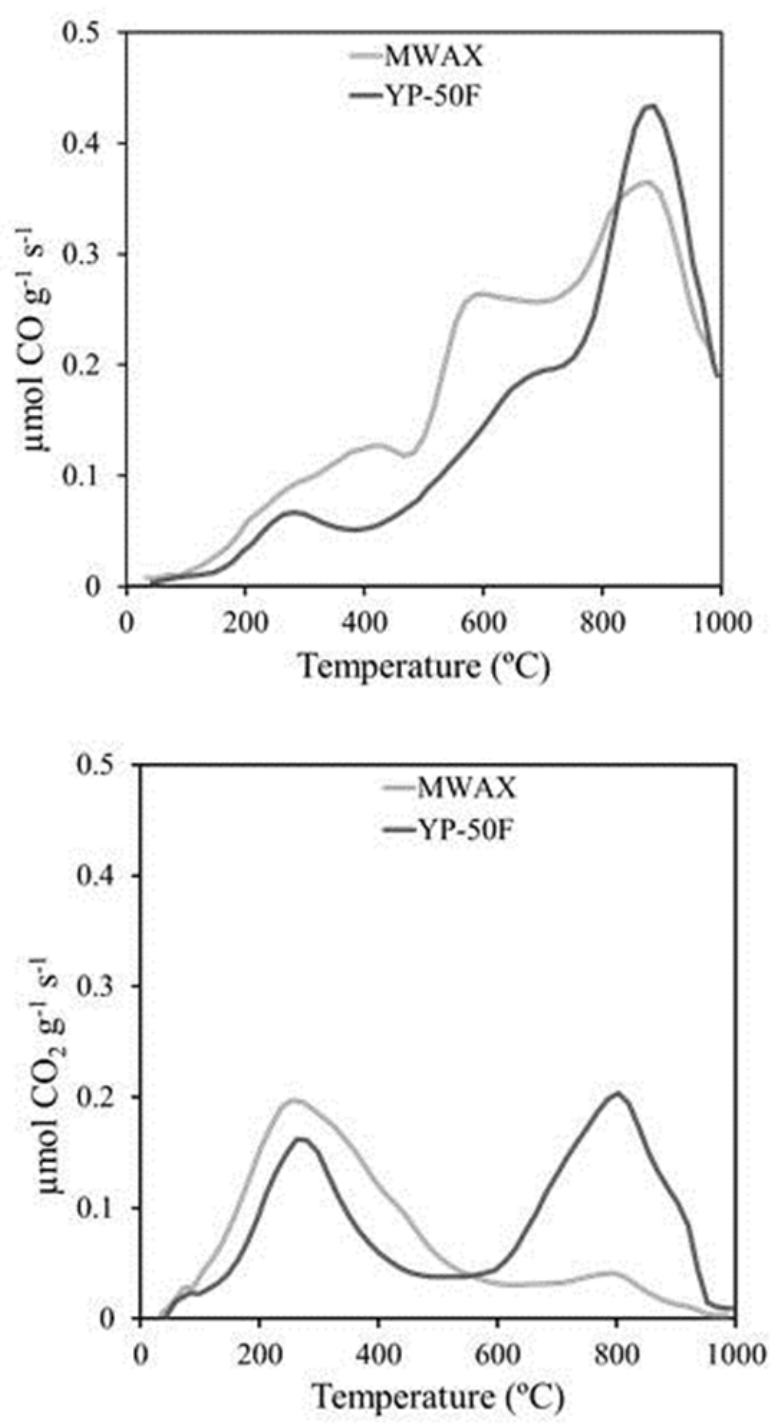

Figure 1. CO (a) and $\mathrm{CO}_{2}$ (b) profiles obtained by TPD experiments for MWAX and YP-50F.

With respect to the porosity of the materials, all carbons have a similar microporosity (see Figure S1) and, in consequence, a similar surface area of about $1600 \mathrm{~m}^{2} \mathrm{~g}^{-1}$ (Table 3) It should be noted that the carbon xerogels were activated with the purpose of obtaining surface areas to that of the commercial activated carbon. In this way, this variable can be discarded when comparing the performance of the electrodes in the supercapacitors. The main differences, therefore, are to be found in the mesoporosity of 
the carbons. The carbon xerogels have three times the mesoporosity volume of YP-50F and also larger average mesopore diameters $\left(\mathrm{D}_{\text {meso }}\right)$.

Table 3. Porous properties of the carbons studied obtained from the $\mathbf{N}_{2}$ adsorptiondesorption isotherms

\begin{tabular}{lllll}
\hline SAMPLE & $\begin{array}{l}\mathrm{Vp} \\
\left(\mathrm{cm}^{3} \mathrm{~g}^{-1}\right)\end{array}$ & $\begin{array}{l}\text { Vmeso } \\
\left(\mathrm{cm}^{3} \mathrm{~g}^{-1}\right)\end{array}$ & $\begin{array}{l}\text { Dmeso } \\
(\mathrm{nm})\end{array}$ & $\begin{array}{l}\mathrm{S}_{\mathrm{BET}} \\
\left(\mathrm{m}^{2} \mathrm{~g}^{-1}\right)\end{array}$ \\
\hline MWAX & 1.1 & 0.5 & 6.9 & 1599 \\
MWAX-1 & 1.2 & 0.6 & 7.0 & 1669 \\
MWAX-2 & 1.2 & 0.6 & 8.7 & 1556 \\
\hdashline YP-50F & 0.8 & 0.2 & 2.1 & 1679 \\
\hline
\end{tabular}

Comparison of the three carbon xerogels shows that a wider mesoporous size distribution occurs when the organic xerogel is doped with $0.22 \mathrm{wt} \%$ of GO (Figure $2 \mathrm{a}$ ), which suggests that during the microwave gelation step, sample MWOX undergoes a more severe collapse of its porous structure than when GO is added (MWOX-0.46). Although after the carbonization/activation process the mesopores experience a slight shrinkage $[31,32]$, the differences in the pore size distributions of both samples are preserved (Figure 2b). This "anti-shrinkage" effect of GO addition observed in this work confirms the findings of Guo et al. [33]. However, this does not seem to be the case when $0.11 \mathrm{wt} \%$ of $\mathrm{GO}$ is added to the initial solution. Thus, the pore size distributions of MWOX-0.23 and MWOX are very similar (Figure 2c) and they remain so even after the activation process, (Figure $2 \mathrm{~d}$ ). The explanation seems to be that, although the addition of GO gives rise to a wider pore size distribution, a minimum amount is needed, at least more than $0.11 \mathrm{wt} \%$ in the present case, for this to occur. 

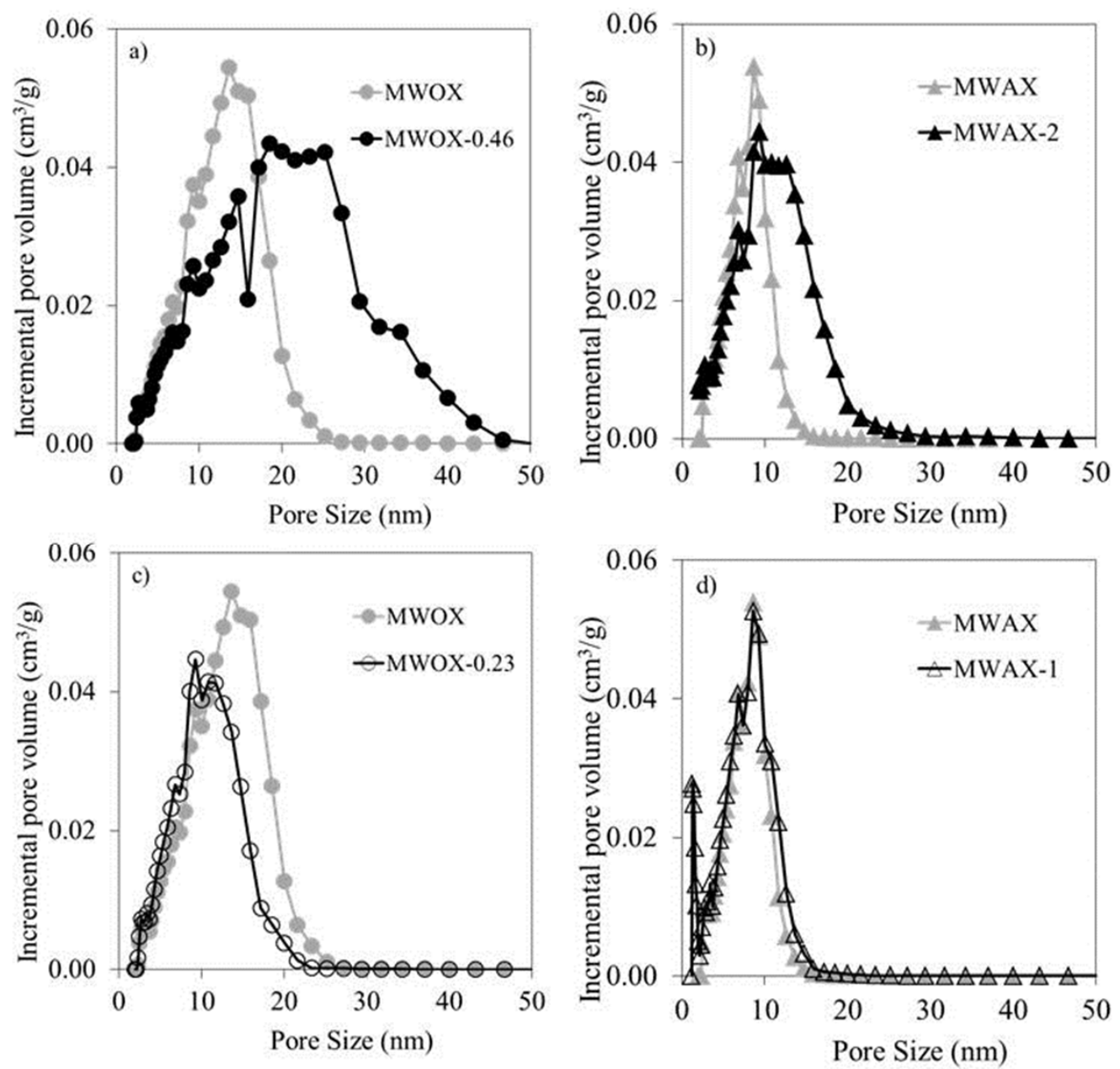

Figure 2. Pore size distribution of the organic (a,c) and activated (b,d) xerogels studied.

Figure 3 shows HRTEM images of the nanostructures of the carbons. The first most remarkable feature about these images is that all the materials are composed of carbon sheets of less than $10 \mathrm{~nm}$ that are randomly ordered but interconnected with each other. On the other hand, if MWAX and YP50-F are compared (Figures 3a and 3d respectively) it seems that in the carbon xerogel these carbon nano-sheets are more densely packed than those of the reference active carbon, which shows some voids. The presence of these discontinuities, that disconnect the (conductive) carbon sheets, appears to be the only reason why the electrical conductivity of MWAX is more than twice that of YP50-F (see Table 4). 

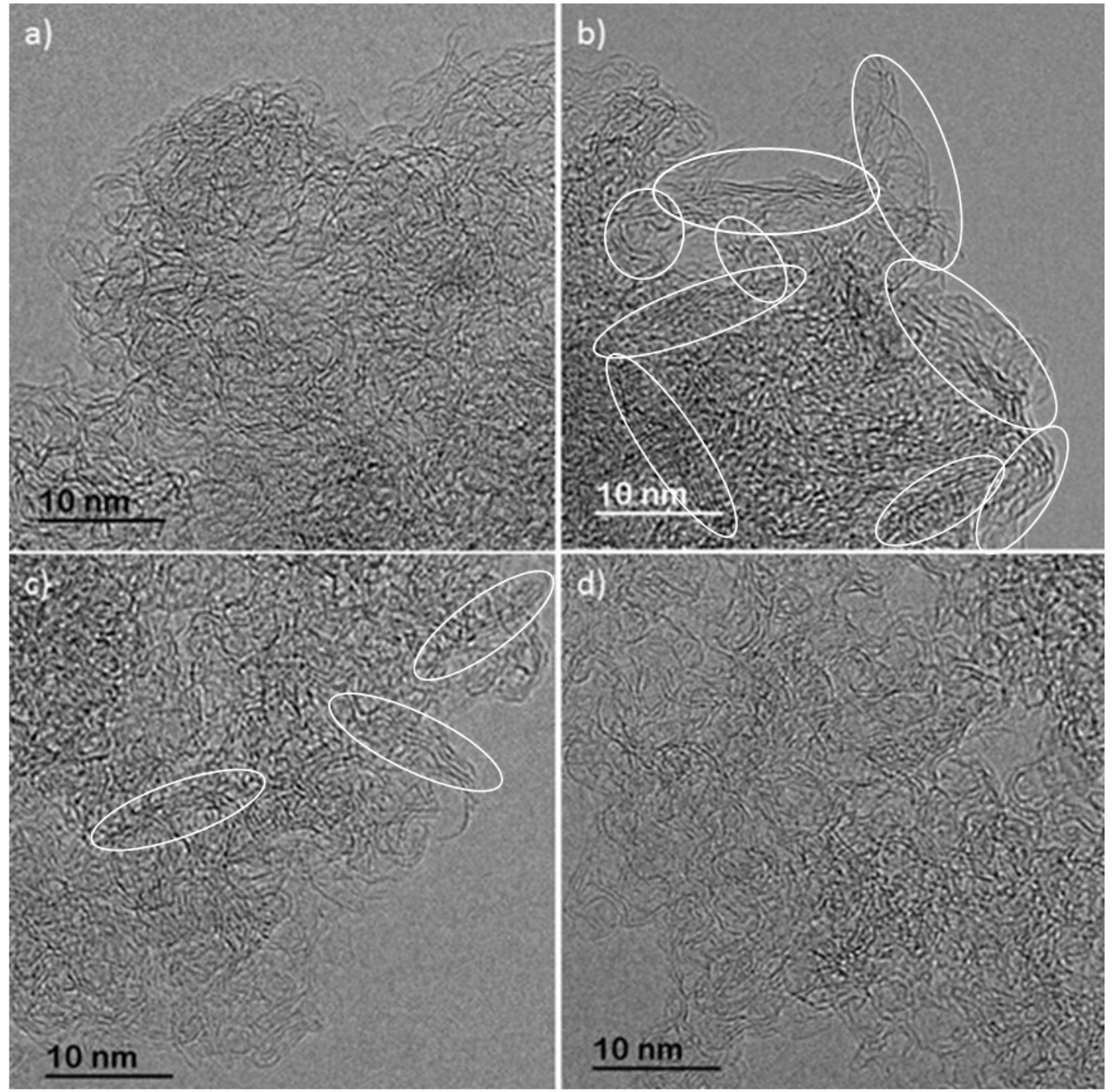

Figure 3. HRTEM images of the carbons studied a) MWAX b) MWAX-2 c) MWAX-1 d) YP-50F. Highlighted areas correspond to large (i.e. > $10 \mathrm{~nm}$ ) ordered domains (graphene layers). More HRTEM images of these samples can be seen in the video of the supplementary material.

The nanostructures of the graphene-doped samples (Figures $3 b$ and $3 c$ ) differ from that of the carbon xerogel (Figure 3a) in that they are made up of graphene layers of length $>10 \mathrm{~nm}$ embedded in the smaller nano-sheets $(<10 \mathrm{~nm})$. Moreover, while in MWAX-2 (Figure 3b) the graphene layers are interconnected, those in MWAX-1 seem to be scattered. This suggests that the addition of $0.11 \mathrm{wt} \%$ of GO to the precursor solution is 
not enough for the graphene sheets to reach their percolation threshold whereas the addition of $0.22 \mathrm{wt} \%$ is. This is reflected in the electrical conductivities exhibited by these materials. Thus, sample MWAX-1, in which the embedded graphene does not reach its electric percolation threshold, has an electrical conductivity similar to that of sample MWAX. However, MWAX-2, which has graphene sheets linked throughout the whole of its carbon structure, displays an electrical conductivity that is three times higher than that of the other two carbon xerogels. It can be concluded therefore that to increase the electrical conductivity of the carbon xerogels it is necessary not only to incorporate graphene into the carbon structure but to do so using a minimum amount so as to allow the electrical percolation threshold to be attained.

Table 4. FPP conductivities of the electrodes prepared with the materials studied

\begin{tabular}{lc}
\hline SAMPLE & $\mathrm{K}\left(\mathrm{S} \mathrm{m}^{-1}\right)$ \\
\hline MWAX & 110 \\
MWAX-1 & 120 \\
MWAX-2 & 310 \\
\hline YP-50F & 50 \\
\hline
\end{tabular}

As will be seen below, the differences in mesopore volume and electrical conductivity of the materials are of paramount importance for when they are used as electrodes in supercapacitors.

The Nyquist plot (Figure S2), where the electrochemical performance of MWAX and MWAX-2 is compared, shows that in the low frequency range, the imaginary part of the impedance tends to a vertical line characteristic of a double layer capacitive behavior in both cases. Nevertheless, at high frequencies more differences are observed. The internal resistance of the MWAX-2 supercapacitor is lower than MWAX, as the Nyquist plot is shifted on the real impedance axis towards lower values (i.e., 0.06 and $0.11 \Omega$ 
$\mathrm{cm}^{2}$ for MWAX-2 and MWAX, respectively). Furthermore, the $45^{\circ}$ Warburg region, is considerably longer in the case of MWAX, therefore the resistance of ion transport within it porous structure is also bigger for these sample. This results are in totally accordance with the electrical conductivity measurements of the electrodes (Table 4) and will be determinant for the electrochemical behavior of these samples as supercapacitors.

Figure 4 shows the variation of the capacitance with the current density (from $0.1 \mathrm{Ag}^{1}$ to $16 \mathrm{~A} \mathrm{~g}^{-1}$ ) of the graphene-doped carbon xerogel (MWAX-2), the undoped one (MWAX) and the reference active carbon (YP-50F). As can be seen, at low current density $\left(0.1 \mathrm{~A} \mathrm{~g} \mathrm{~g}^{-1}\right)$ the capacitance of the three materials is similar (the $\mathrm{CV}$ plots at 2 $\mathrm{mV} \mathrm{s}^{-1}$ also show high similarity, see Figure S3). However, differences become more prominent as the current density increases.

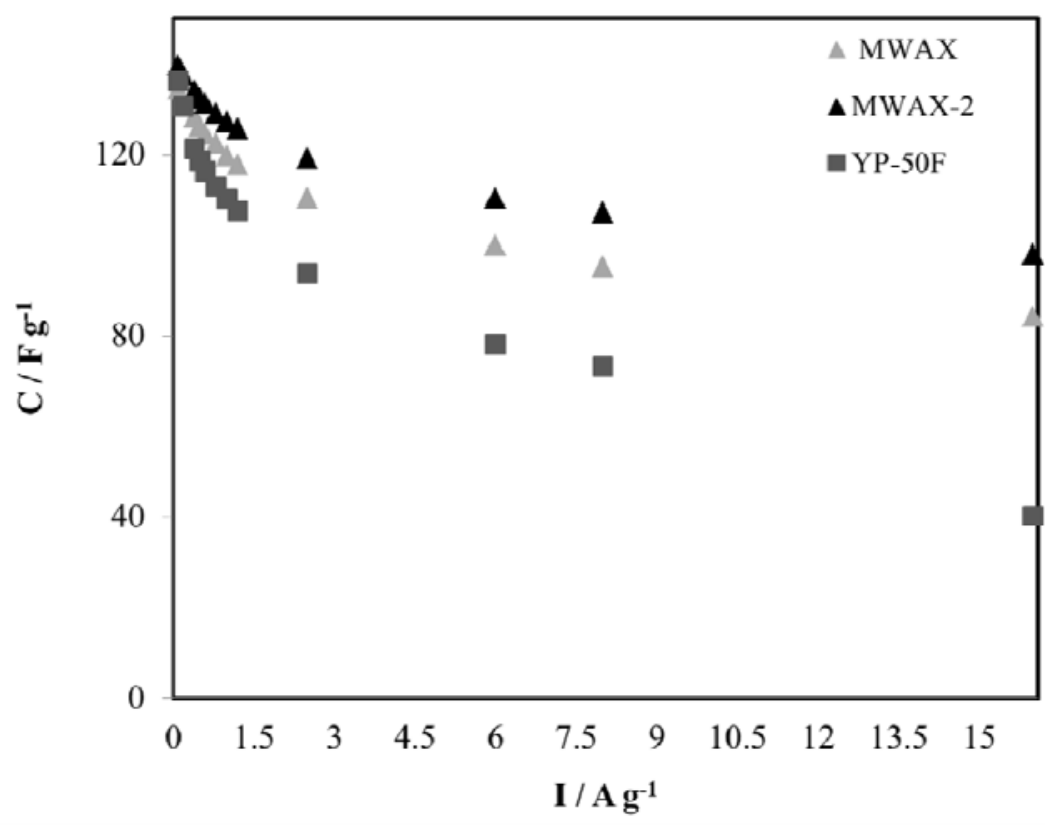

Figure 4. Capacitance behaviour as a function of current density with $U=1 \mathrm{~V}$ of the activated xerogels studied and the reference material. 
It is important to note here that, although capacitances are frequently reported at low intensities (commonly at $0.2 \mathrm{~A} \mathrm{~g}^{-1}$ ), this is a sufficiently favourable working condition for a supercapacitor. The reason for this is that most supercapacitors are designed to charge and discharge (i.e. high power) quickly, in many cases in a matter of seconds instead of several minutes. Thus, a charge/discharge cycle at $0.2 \mathrm{~A} \mathrm{~g}^{-1}$ takes 15 minutes while at $16 \mathrm{~A} \mathrm{~g} \mathrm{~g}^{-1}$ it takes only 5 seconds. In other words, in many situations (for instance, when supercapacitors are used in regenerative braking in automotive applications) it is more important for a supercapacitor to be able to store quickly as much charge as possible, than to offer its maximum capacitance.

Coming back to Figure 4, it can be seen that MWAX-2 experiences the lowest capacitance drop and has the highest capacitance when the supercapacitor is working at high intensity values $\left(98 \mathrm{~F} \mathrm{~g}^{-1}\right.$ at $16 \mathrm{~A} \mathrm{~g}^{-1}$, which is $28.5 \%$ less than its initial capacitance), while MWAX and YP-50F undergoes a capacity drop of $34 \%$ and $69 \%$ respectively. Thus, at $16 \mathrm{~A} \mathrm{~g}^{-1}$, the graphene-doped carbon xerogel MWAX-2 has a capacitance that is approximately $25 \%$ and $150 \%$ higher than that of MWAX and YP50F respectively.

These differences can be ascribed to their differences in electrical conductivity and mesoporosity.

Comparison of the two carbon xerogels shows that both of them have very similar porous properties (Table 3). Their $\mathrm{V}_{\text {micro }}$ and $\mathrm{V}_{\text {meso }}$ are similar and, although the Dmeso of MWAX-2 is slightly wider (just $0.1 \mathrm{~nm}$ on average, as reported in Table 3 ), this is probably not enough to explain the difference in their capacitances. Thus, the $25 \%$ higher capacitance of the doped carbon must be attributed to the fact that its electrical conductivity is three times that of the undoped carbon xerogel (see Table 4). It is clear 
that good conductive materials are required for the transfer of the charge to take place (i.e. so that the ions can move without obstruction thorough the mesopores and access the micropores where the charge is stored). This is of great importance as the higher the electrical conductivity of the carbon electrode is, the lower the contact resistance, which is what enables a fast charge transfer to take place [7-9]. Therefore, as MWAX-2 is more conductive than the undoped carbon xerogel, (i.e., when high current densities are applied more ions are able to reach the micropore network), its capacitance is higher (Figure 4).

To sum up, the two carbon xerogels have similar chemical compositions and porous textures, but the electrical conductivity of the graphene-doped carbon triples that of the undoped one, which gives it a $25 \%$ greater capacitance. Thus, the fact that the electrical conductivity of MWAX is "only" twice that of YP-50F does not seem to be sufficient enough reason to explain the $100 \%$ increase in capacitance at $16 \mathrm{~A} \mathrm{~g}^{-1}$ (see Figure 4). Such a huge enhancement must be due to some other cause. In fact, the superior capacitances of the carbon xerogels are mainly due to the fact that, although all the carbons have similar micropore volumes (all of them have a $\mathrm{S}_{\mathrm{BET}}$ of ca. $1600 \mathrm{~m}^{2} / \mathrm{g}$ ), the carbon xerogels are also mesoporous, whereas YP-50F is essentially microporous. Mesopores act as transport pores that facilitate the movement of the electrolyte ions when they diffuse into the micropores during the charging of the supercapacitor. Moreover, the diameter of the mesopores has to be wide enough to facilitate the passage of the ions [12-14, 34]. In summary, the much higher $\mathrm{V}_{\text {meso }}$ of the carbon xerogels provides them with a mesopore network that facilitates the rapid charging of the supercapacitor, resulting in much higher capacitances in shorter charging times (i.e. at high current density). 
According to Equation 2, energy density (E) is directly proportional to capacitance (since the power-operated window is $1 \mathrm{~V}$ in all cases). Therefore, the line of reasoning developed above must also be valid for explaining the differences in the energy densities of the supercapacitors when YP-50F, MWAX and MWAX-2 are used as electrodes. As can be seen in the Rangone plot (Figure 5), the energy densities are $6 \mathrm{Wh}$ $\mathrm{kg}^{-1}, 12 \mathrm{Wh} \mathrm{kg}^{-1}$ and $15 \mathrm{Wh} \mathrm{kg}^{-1}$ for YP-50F, MWAX and MWAX-2, respectively, which mirrors the same increments as in the case of the capacitances, i.e. $100 \%$, (MWAX with respect to YP-50F,) and 25\% (MWAX-2 with respect to MWAX).

The differences between the materials, in particular the differences in electrical conductivity, have even a greater repercussion on the power densities of the supercapacitors. As can be seen in Figure 5 the power densities of carbons YP-50F, MWAX and MWAX-2.5 are ca. $8000 \mathrm{~W} \mathrm{~kg}^{-1}, 21000 \mathrm{Wkg}^{-1}$ and $42000 \mathrm{~W} \mathrm{~kg}^{-1}$ respectively, which represent increases in power density of $162.5 \%$, (MWAX with respect to YP-50F), 100\% (MWAX-2 with respect to MWAX) and 425\% (MWAX-2 with respect to YP-50F).

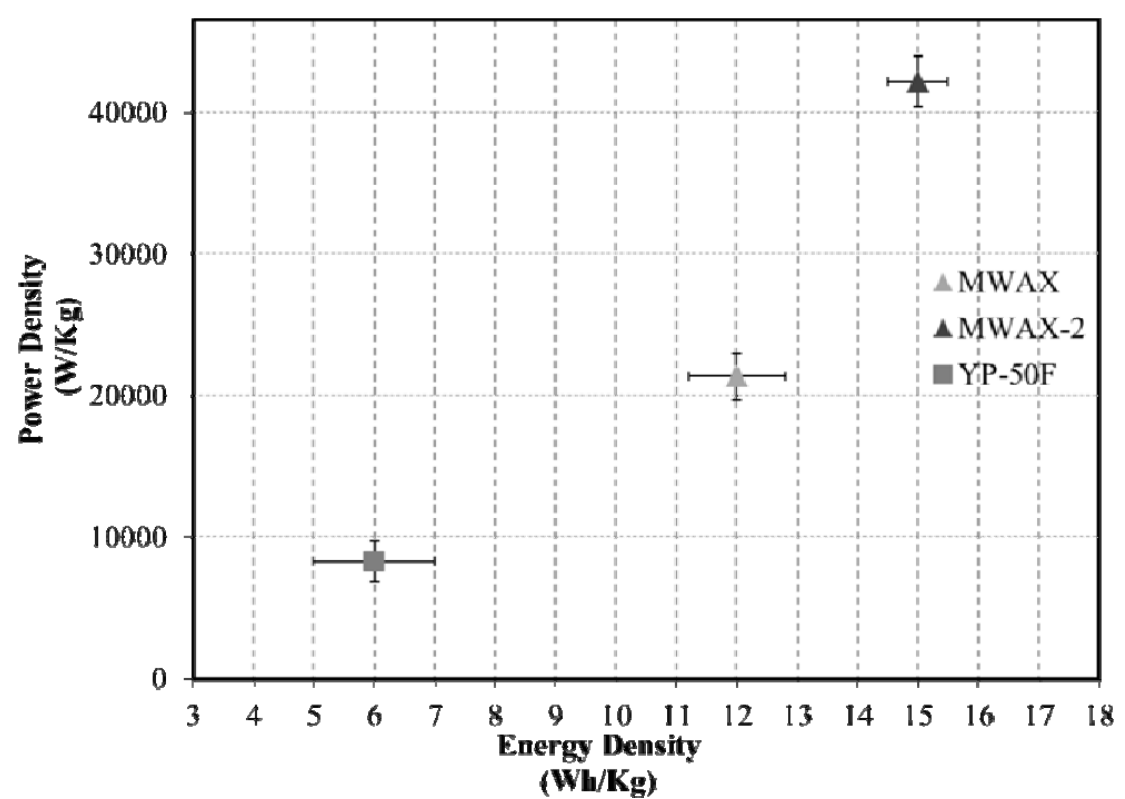


Figure 5. Ragone plot for the supercapacitors assembled with the tested carbon materials. Energy and Power densities were calculated at $16 \mathrm{Ag}^{-1}$, using equations (2) and (3) respectively. Results correspond to a mean of 3 different samples.

In other words, a $2.5 \mathrm{wt} \%$ doping of graphene gives the supercapacitor twice as much power density as the undoped carbon xerogel. This enormous effect can be explained in terms of how the electrical conductivity (tripled by graphene doping) affects the power density. Thus, in equation 3 it can be seen that the power density is inversely proportional to the equivalent series resistance (ESR) multiplied by a factor of 4 . Taking into account that the ESR depends on (i) the resistance of the active material used as electrode (i.e. ionic diffusion resistance), (ii) the resistance of the electrolyte and (iii) the resistance of the assembly of the supercapacitor cell (which depends on the electrode/substrate contact, the nature of the current collector and/or the separator sheets, etc.), it seems clear that the variances of ESR , and therefore of power density, must be due to the differences in the ionic diffusion resistance of the materials used, because the electrolytes and the assemblies are identical in all the samples. In short, the greater the electrical conductivity of the active material, the faster the diffusion of the ions in the electrode, as a result of which the ESR is reduced and high power densities are obtained $[9,12,13]$.

\section{Conclusions}

A graphene-doped carbon xerogel that displays a superior behaviour as active material in supercapacitor electrodes has been produced by a simple, fast and cost-effective method. At a nanometric scale the carbon shows a structure with interconnected graphene lamellae embedded into the carbon xerogel matrix. The addition of a 
minimum amount $(0.22 \mathrm{wt} \%)$ of graphene oxide to the precursor solution is enough to attain the percolation threshold in the graphene-doped carbon xerogel, leading to an increase electric conductivity which triples that of the non-doped carbon xerogel. Doping with graphene oxide causes a slight increase in the mesopore size (due to a lower shrinkage during the synthesis as a result of the better mechanical properties of the doped sample) with respect to the non-doped carbon xerogels. The importance of the mesoporosity these electrode materials for the performance of supercapacitors (usually underestimated due to the importance attached to the microporosity and surface area) has also been demonstrated. The resulting graphene-doped carbon xerogel combines high (micro and meso) porosity, provided by the carbon xerogel matrix, and elevated conductivity, afforded by the graphene sheets embedded into this matrix. In consequence, the graphene-doped carbon supercapacitors present higher specific capacitances and powers which become particularly relevant at high current densities.

\section{Acknowledgments}

The authors gratefully acknowledge the financial support of the Ministerio de Economía

y Competitividad of Spain, MINECO (Project CTQ2014-54772-P) and CTQ201344213-R), and Generalitat Valenciana for project PROMETEOII/2014/007).

\section{References}

[1] U.S. Department of Energy: Energy Storage Safety Strategic Plan, Office of Electricity Delivery and Energy Reliability 2014. 
[2] P.J. Hall, E.J. Bain, Energy-storage technologies and electricity generation, Energy Policy 36(12) (2008) 4352-4355.

[3]. B.E. Conway. Electrochemical Supercapacitors: Scientific Fundamentals and Technological Applications. Kluwer Academic Plenum, New York 1999

[4] P.S. Fernández, E.B. Castro, S.G. Real, A. Visintin, A. Arenillas, E.G. Calvo, E.J. Juárez-Pérez, A.J. Menéndez, M.E. Martins, Electrochemical behavior and capacitance properties of carbon xerogel/multiwalled carbon nanotubes composites, Journal of Solid State Electrochemistry 16(3) (2012) 1067-1076.

[5] X.H. Xia, X.F. Zhang, S.Q. Yi, H.B. Liu, Y.X. Chen, H. Chen, L. Yang, Y.D. He, Preparation of high specific surface area composite carbon cryogels from self-assembly of graphene oxide and resorcinol monomers for supercapacitors, Journal of Solid State Electrochemistry 20(6) (2016) 1793-1802.

[6] F. Meng, X. Zhang, B. Xu, S. Yue, H. Guo, Y. Luo, Alkali-treated graphene oxide as a solid base catalyst: Synthesis and electrochemical capacitance of graphene/carbon composite aerogels, Journal of Materials Chemistry 21(46) (2011) 18537-18539.

[7] Z.M. Marković, B.M. Babić, M.D. Dramićanin, I.D. Holclajtner Antunović, V.B. Pavlović, D.B. Peruško, B.M. Todorović Marković, Preparation of highly conductive carbon cryogel based on pristine graphene, Synthetic Metals 162(9-10) (2012) 743-747. [8] L. Liu, J. Yang, Q. Meng, Graphene cross-linked phenol-formaldehyde hybrid organic and carbon xerogel during ambient pressure drying, Journal of Sol-Gel Science and Technology 66(1) (2013) 1-5.

[9] Z. Ling, G. Wang, Q. Dong, B. Qian, M. Zhang, C. Li, J. Qiu, An ionic liquid template approach to graphene-carbon xerogel composites for supercapacitors with enhanced performance, Journal of Materials Chemistry A 2(35) (2014) 14329-14333. 
[10] T.T. Chen, W.L. Song, L.Z. Fan, Engineering graphene aerogels with porous carbon of large surface area for flexible all-solid-state supercapacitors, Electrochimica Acta 165 (2015) 92-97.

[11] Y. Zhu, S. Murali, M.D. Stoller, K.J. Ganesh, W. Cai, P.J. Ferreira, A. Pirkle, R.M. Wallace, K.A. Cychosz, M. Thommes, D. Su, E.A. Stach, R.S. Ruoff, Carbon-based supercapacitors produced by activation of graphene, Science 332(6037) (2011) 15371541.

[12] G.R. Wencui Li , J. Fricke, Carbon aerogels derived from cresol-resorcinolformaldehyde for supercapacitors, Carbon 40 (2002) 2955-2959.

[13] E. Frackowiak, G. Lota, J. Machnikowski, C. Vix-Guterl, F. Béguin, Optimisation of supercapacitors using carbons with controlled nanotexture and nitrogen content, Electrochimica Acta 51(11) (2006) 2209-2214.

[14] E.G. Calvo, F. Lufrano, P. Staiti, A. Brigandì, A. Arenillas, J.A. Menéndez, Optimizing the electrochemical performance of aqueous symmetric supercapacitors based on an activated carbon xerogel, J Power Sources 241 (2013) 776-782.

[15] M. Sevilla, G.A. Ferrero, A.B. Fuertes, Beyond KOH activation for the synthesis of superactivated carbons from hydrochar, Carbon 114 (2017) 50-58.

[16] M. Seredych, E. Rodríguez-Castellõn, T.J. Bandosz, Peculiar properties of mesoporous synthetic carbon/graphene phase composites and their effect on supercapacitive performance, ChemSusChem 8(11) (2015) 1955-1965.

[17] A. Barroso-Bogeat, M. Alexandre-Franco, C. Fernández-González, J. SánchezGonzález, V. Gómez-Serrano, Electrical conductivity of metal (hydr)oxide-activated carbon composites under compression. A comparison study, Materials Chemistry and Physics 152 (2015) 113-122. 
[18] S. Nardecchia, D. Carriazo, M.L. Ferrer, M.C. Gutierrez, F. del Monte, Three dimensional macroporous architectures and aerogels built of carbon nanotubes and/or graphene: synthesis and applications, Chemical Society Reviews 42(2) (2013) 794-830. [19] P. Dong, T. Maneerung, W.C. Ng, X. Zhen, Y. Dai, Y.W. Tong, Y.-P. Ting, S.N. Koh, C.-H. Wang, K.G. Neoh, Chemically treated carbon black waste and its potential applications, Journal of Hazardous Materials 321 (2017) 62-72.

[20] H.O. Pierson, Handbook of carbon, graphite, diamond and fullerenes Properties, Processing and

Applications, Noyes Publications (1993) 61.

[21] N. Rey-Raap, E.G. Calvo, J.M. Bermúdez, I. Cameán, A.B. García, J.A. Menéndez, A. Arenillas, An electrical conductivity translator for carbons, Measurement: Journal of the International Measurement Confederation 56 (2014) 215218.

[22] E.G. Calvo, N. Ferrera-Lorenzo, J.A. Menéndez, A. Arenillas, Microwave synthesis of micro-mesoporous activated carbon xerogels for high performance supercapacitors, Microporous and Mesoporous Materials 168 (2013) 206-212.

[23] L. Zubizarreta, A. Arenillas, J.A. Menéndez, J.J. Pis, J.P. Pirard, N. Job, Microwave drying as an effective method to obtain porous carbon xerogels, Journal of Non-Crystalline Solids 354(33) (2008) 4024-4026.

[24] L. Liu, G. Tian, R. Ma, G. Pan, W. You, Q. Meng, Preparation and electrosorption performance of graphene xerogel, ECS Solid State Letters 4(6) (2015) M9-M11.

[25] K. Zhang, B.T. Ang, L.L. Zhang, X.S. Zhao, J. Wu, Pyrolyzed graphene oxide/resorcinol-formaldehyde resin composites as high-performance supercapacitor electrodes, Journal of Materials Chemistry 21(8) (2011) 2663-2670. 
[26] I. Rodriguez-Pastor, G. Ramos-Fernandez, H. Varela-Rizo, M. Terrones, I. MartinGullon, Towards the understanding of the graphene oxide structure: How to control the formation of humic-and fulvic-like oxidized debris, Carbon 84(1) (2015) 299-309.

[27] E.G. Calvo, N. Rey-Raap, A. Arenillas, J.A. Menéndez, The effect of the carbon surface chemistry and electrolyte $\mathrm{pH}$ on the energy storage of supercapacitors, RSC Advances 4(61) (2014) 32398-32404.

[28] T. Brousse, M. Toupin, D. Bélanger, A Hybrid Activated Carbon-Manganese Dioxide Capacitor using a Mild Aqueous Electrolyte, Journal of the Electrochemical Society 151(4) (2004).

[29] J.L. Figueiredo, M.F.R. Pereira, The role of surface chemistry in catalysis with carbons, Catalysis Today 150(1-2) (2010) 2-7.

[30] J.L. Figueiredo, M.F.R. Pereira, M.M.A. Freitas, J.J.M. Órfão, Modification of the surface chemistry of activated carbons, Carbon 37(9) (1999) 1379-1389.

[31] M.S. Contreras, C.A. Páez, L. Zubizarreta, A. Léonard, S. Blacher, C.G. OliveraFuentes, A. Arenillas, J.-P. Pirard, N. Job, A comparison of physical activation of carbon xerogels with carbon dioxide with chemical activation using hydroxides, Carbon 48(11) (2010) 3157-3168.

[32] L. Zubizarreta, A. Arenillas, A. Domínguez, J.A. Menéndez, J.J. Pis, Development of microporous carbon xerogels by controlling synthesis conditions, Journal of NonCrystalline Solids 354(10-11) (2008) 817-825.

[33] K. Guo, H. Song, X. Chen, X. Du, L. Zhong, Graphene oxide as an anti-shrinkage additive for resorcinol-formaldehyde composite aerogels, Physical Chemistry Chemical Physics 16(23) (2014) 11603-11608. 
[34] E.G. Calvo, C.O. Ania, L. Zubizarreta, J.A. Menendez, A. Arenillas, Exploring New Routes in the Synthesis of Carbon Xerogels for Their Application in Electric Double-Layer Capacitors, Energy \& Fuels 24 (2010) 3334-3339. 